\title{
Experimental Verification of Hypothesis of Antitumor Potential Presence in Mesenchymal Stem Cells
}

\author{
Kulchitsky Vladimir*1, Zamaro Alexandra ${ }^{1}$, Shanko Yuri ${ }^{2}$, Suziedelis Kestusis ${ }^{3}$, Kaliadzich Zhanna ${ }^{4}$, \\ Pashkevich Svetlana ${ }^{1}$, Kuznetsova Tatiana ${ }^{1}$, Takalchyk Yulya ${ }^{1}$, Dosina Margarita ${ }^{1}$, Pašukonienẻ Vita ${ }^{3}$, \\ Krivenchuk Dmitry ${ }^{1}$, Navitskaya Valeria ${ }^{2}$, Khotin Vitaly ${ }^{1}$ and Koulchitsky Stanislav ${ }^{5}$ \\ ${ }^{1}$ Institute of Physiology, National Academy of Sciences, Europe \\ ${ }^{2}$ Republican Scientific and Practical Center of Neurology and Neurosurgery, Europe \\ ${ }^{3}$ National Cancer Institute, Vilnius, Lithuania, Europe \\ ${ }^{4}$ NN Alexandrov National Cancer Centre, Europe \\ ${ }^{5}$ Liege University, Liege, Belgium, Europe \\ *Corresponding author: Kulchitsky Vladimir, Institute of Physiology, National Academy of Sciences, Minsk, Belarus, Europe
}

\begin{tabular}{|c|c|}
\hline ARTICLE INFO & ABSTRACT \\
\hline Received: 幽 January 11, 2020 & Abbreviations: C6 Glioma: A Rat Cell Line of Astrocytic Origin; DMEM: Dulbecco's Mod- \\
\hline Published: 蔧 January 22, 2020 & $\begin{array}{l}\text { ified Eagle's Medium; F10 Medium: F-10 Nutrient Medium; MSCs: Mesenchymal Stem } \\
\text { Cells; SCs: Stem Cells }\end{array}$ \\
\hline
\end{tabular}

Citation: Kulchitsky Vladimir, Zamaro Alexandra, Shanko Yuri, Suziedelis Kestusis, Kaliadzich Zhanna, et al. PExperimental Verification of Hypothesis of Antitumor Potential Presence in Mesenchymal Stem Cells. Biomed J Sci \& Tech Res 24(5)-2020. BJSTR. MS.ID.004107. Cells; SCs: Stem Cells

\section{Introduction}

The prospects for Stem Cells (SCs) use in solid tumor for therapeutic purposes are debatable in scientific literature [1-5]. On the one hand, SCs are considered as convenient transporters of anticancer substances to tumor cells [6-9]. On the other hand, experts fear an enhancement of carcinogenesis process during SCs introduction into the body $[1,3,10]$. There are several additional aspects of this problem. Protective potential of the body and, first, the activity of immune system play an important role during tumor development. It is advisable to consider immunosuppressive effect of Mesenchymal SCs (MSCs) [11,12], which is a troubling argument in the idea of MSCs antitumor use. Scientists recognize and pay attention to this natural aspect of the problem (immunosuppressive effect), which is considered when evaluating recommendations for antitumor therapy. On the other hand, clinicians are interested in protective and restorative potential of MSCs, which has been demonstrated in conditions of trauma, hypoxia or development of inflammatory processes [13-15]. Will the positive protective properties of MSCs be manifested in relation to such a pathological process that destroys body tissues as a malignant neoplasm? The work focuses on experimental and clinical facts that indicate protective role of MSCs in the central nervous system [11,13-15]. Currently, knowledge about the reparative potential of MSCs, manifested in the restoration of neural networks in the brain and spinal cord after pathological processes, has been expanded by evidence of the involvement of MSCs in the mechanisms of brain plasticity [13-15], as well as in repair of damaged tissues of other internal organs [16]. There is poor information in the literature $[1,3]$, indicating new protective abilities of SCs, which can be both a 
source of neoplasms (for example, from stem cancer cells) $[17,18]$ and actively fight against tumor cells $[3,18,19]$. The last aspect of the problem supplements modern ideas about the endogenous potential of the body in opposing the carcinogenesis process. Experiments were performed on Wistar rats to verify conditions for implementation of this hypothesis and assess the behavior of MSCs when modeling a tumor process in brain.

\section{Materials and Methods}

In vivo experiments were performed on 28 male Wistar rats weighing 210-240 grams. All rats $(n=28)$ were fixed in stereotaxis under ketamine-xylazine-acepromazine anesthesia. Local craniotomy was performed on the right side of the skull $(0.8 \mathrm{~mm}$ caudal from Bregma, $4.5 \mathrm{~mm}$ lateral to the midline and $3.5 \mathrm{~mm}$ deep from the brain surface). All rats $(\mathrm{n}=28)$ were subjected to implantation of 2.8x105 C6 glioma cells in $20 \mu \mathrm{l}$ of F10 medium into the brain. 14 rats (group 1) were implanted with $40 \times 104$ MSCs in $40 \mu \mathrm{l}$ of low glucose DMEM medium in submucosa of nasal cavity during the operation. Remaining rats ( $n=14$, group 2) received $40 \mu \mathrm{l}$ of low glucose DMEM without stem cells into nasal cavity submucosa. Survival rate of the animals after manipulations was evaluated. All the rats of the first group systematically received 40x104 MSCs in $100 \mu \mathrm{l}$ of low glucose DMEM medium intranasally in the form of spray once per week after surgery. No additional manipulations were performed in the second group. All the 28 rats were alive in two weeks after surgery. One rat was selected from each group and decapitated under Rausch anesthesia at this stage of observation.
Rat's brain was removed from cranial cavity and $8 \mu \mathrm{m}$ slices were made on a freezing microtome (HM525, Germany) for histological studies. Frozen slices were stained with hematoxylin and eosin according to the protocol (http://www.ihcworld.com/_protocols/ special_stains/h\&e_ellis.htm)and Nissl (http://www.ihcworld. com/_protocols/special_stains/nissl-frozen-section.htm).

\section{Results and Discussion}

The growth of glial tumor was revealed in frontotemporal region of right hemisphere of rat's brain from the first group: polymorphic cells (mainly round or elongated) with round or spindle nuclei and scanty cytoplasm (Figure1A). An abundance of blood vessels, mainly of the microvasculature, and focuses of edema were noted in the stroma of tumor (Figure 1B). A neoplasm was also detected in frontotemporal region of right hemisphere in the brain of a rat from the second group. The tumor grows into lateral ventricles of the brain, spreading to the tissue of left hemisphere of the brain (Figures 2A \& 2B). The pia mater of right and left hemispheres of the brain is infiltrated by tumor cells in the area of frontal lobes (Figures 2C \& 2D). Foci of tumor cells were revealed in the cortex of frontal lobes (Figures 2C \& 2D). All the rats from the second group gradually died starting from the 17 th day of observation until the end of the month after the operation. Only three rats out of 14 operated in the first group died by this time of observation (it was considered that one rat from each group was decapitated in two weeks of observation to analyze histological characteristics of animal's brain).

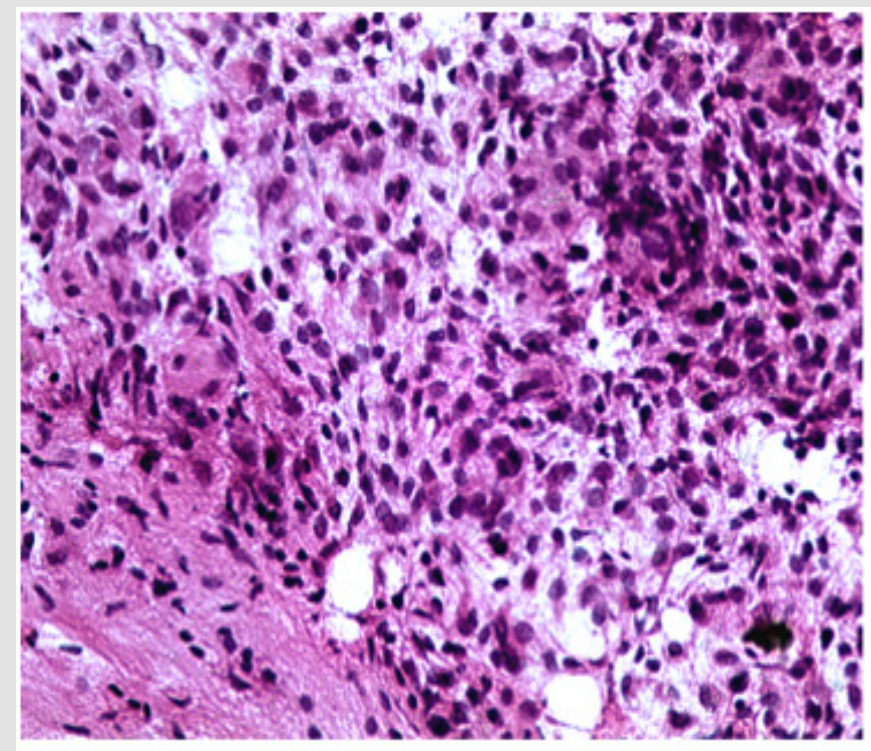

A $(x 400)$

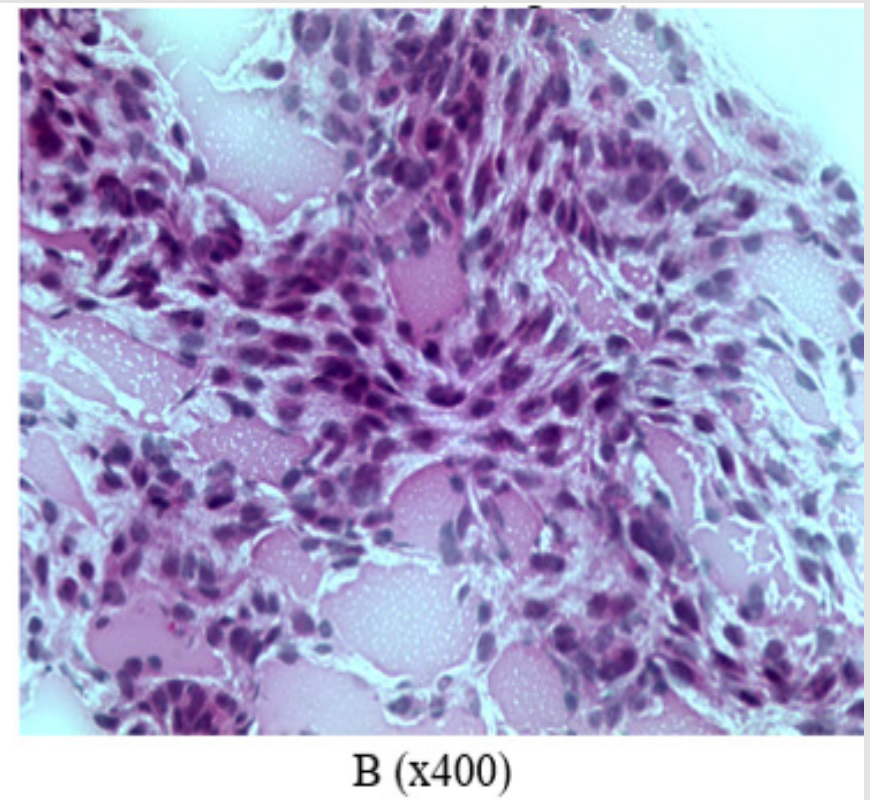

$\mathrm{B}(\mathrm{x} 400)$

Figure 1: Characterization of cellular composition and secondary changes in the tumor of rats from the group 1: A -cell polymorphism, B - abundance of small capillaries (frozen slices, hematoxylin-eosin staining). 

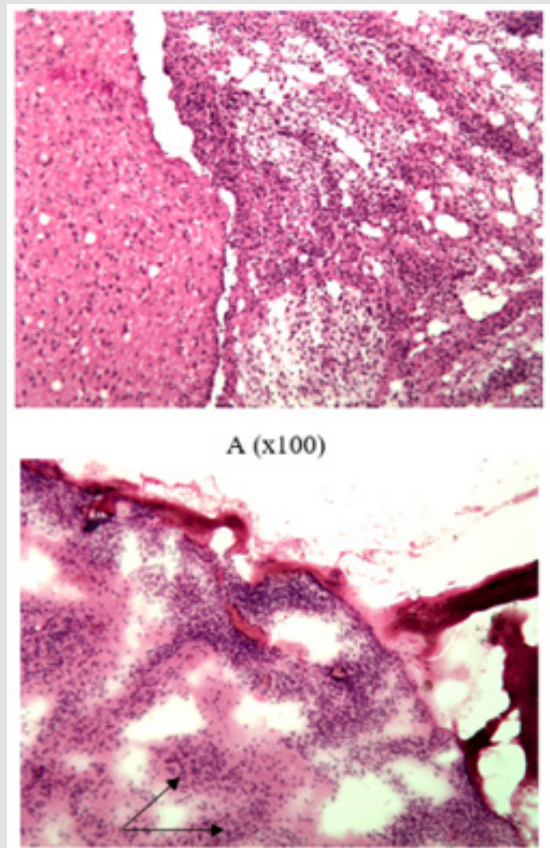

$\mathrm{C}(\mathrm{x} 100)$

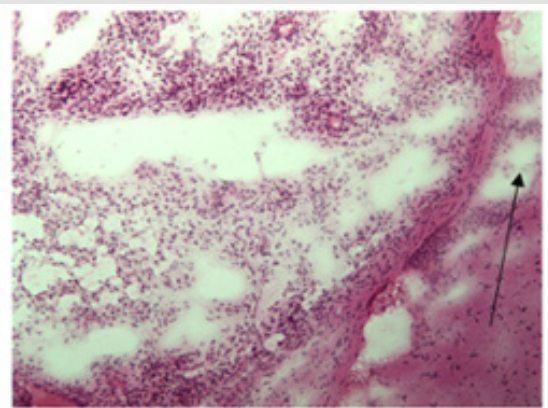

$\mathrm{B}(\mathrm{x} 200)$

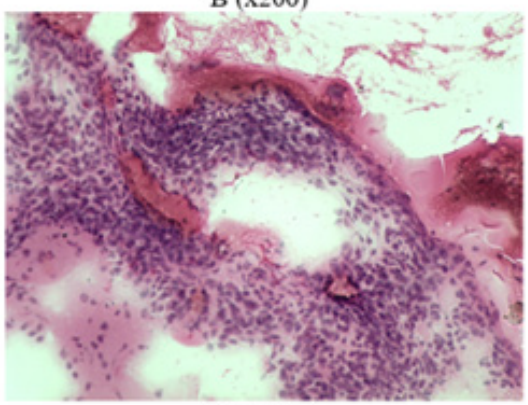

$\mathrm{D}(\mathrm{x} 200)$

Figure 2: Infiltrative tumor growth in group 2: A - tumor growth in lateral ventricles of the brain, B - growth in the left hemisphere (indicated by arrow), C - presence of tumor in the pia mater and frontal cortex (indicated by arrow), D - tumor infiltration in the pia mater (frozen slices, hematoxylin-eosin staining).

Let us recall that the only difference between the groups was the presence of weekly intranasal injections of MSCs in the first group starting from the moment of surgery during implantation of C6 glioma cells into the brain. Therefore, the experiments revealed a difference in viability of rats of the two groups, which received implantation of C6 glioma cells into the brain. All the rats from the second group which were not injected intranasally with MSCs died during first month of observation. 11 out of 14 rats from the first group which were intranasally injected with MSCs survived. Seven rats remained alive after two months of observation. Three rats remained alive after three months of observation. Two rats remained alive after four months of observation. The same two rats remained alive after five months of observation. It was decided to decapitate one of the two rats at this stage of observation for histological examination of brain tissue in the site of C6 glioma cells implantation. Figure 3 shows illustrations of brain tissue at the site of C6 glioma cells implantation 5 months ago. Only careful observation in certain parts of the brain allows finding miniature clusters of cells resembling tumor tissue. It is possible to clearly distinguish a defect in brain tissue after the introduction of micropipette to a depth of $3.5 \mathrm{~mm}$. The remaining rat from the first group where animals received weekly intranasal injections of MSCs is now still alive - for 6 months already from the moment of operation up to the time of writing this article.
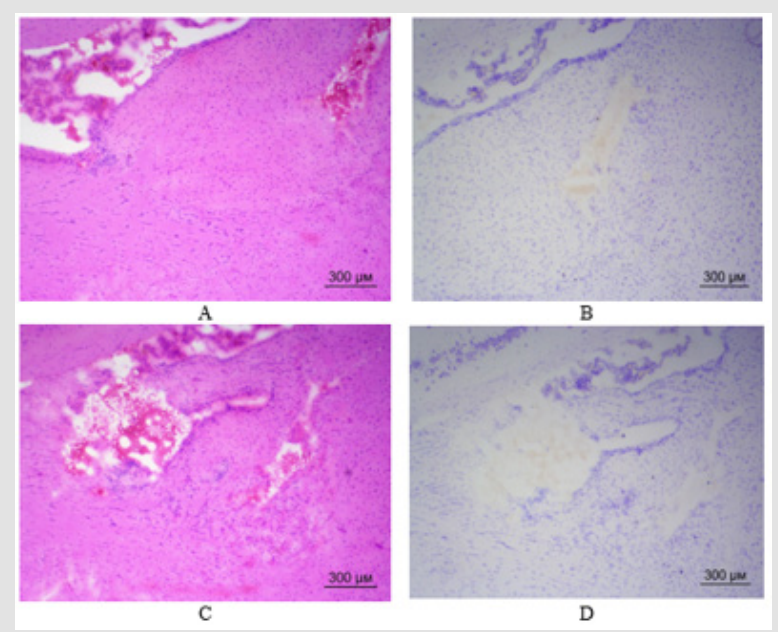

Figure 3: Brain tissue of rat from the first group in the site of C6 glioma cells implantation (frozen slices, hematoxylin-eosin staining - A, C; Nissl staining - B, D): A - a slight accumulation of cells (presumably glioma) on the left side of the figure; B, C, $\mathrm{D}$ - defect in brain tissue at the site of micropipette introduction, no C6 glioma cells detected. (40x magnification). 


\section{Conclusion}

Information is accumulating in the literature stating that MSCs begin to move into the zone of brain neuro destruction after intranasal implantation [13-15]. This aspect is very important for evaluating the obtained experimental data on the survival rate of rats up to six months after implantation of a high-grade C6 glioma tumor into the brain. Given the lifespan of Wistar rats up to three years, a survival period of about one sixth of the animal's life is achieved. We will not try - from an ethical point of view - to compare the median survival rate after development of glioma or glioblastoma in other situations.

\section{Acknowledgement}

Our research project "Molecular markers and Raman spectroscopy for evaluation of correlation between cellular heterogeneity in tumor tissue and primary culture from the tumor tissue" was partially sponsored by Belarus-Lithuania Fund: 20192020 (M19LITG-002) from the State Committee on Science and Technology of the Republic of Belarus, and a grant No. S-LB-19-7 from the Research Council of Lithuania.

\section{Conflict of Interest}

All listed authors concur with the submission of the manuscript; all authors have approved the final version. The authors have no financial or personal conflicts of interest.

\section{References}

1. Bolli R, Hare JM, Henry TD, Lenneman CG, March KL, et al. (2018) Rationale and Design of the SENECA (StEm cell iNjECtion in cAncer survivors) Trial. Am Heart J 201: 54-62.

2. Kulchitsky V, Koulchitsky S (2018) Biomedical prospects for the use of stem cells for the treatment of gliomas. Biomed J Sci \&Tech Res 4(5): 1-3.

3. Zamaro AS, Kaliadzich ZV, Koulchitsky SV, Shanko YG, Suziedelis K, et al. (2019) Stem Cells and Malignant Tumor Cells - Friends or Enemies. J Cancer Sci Treatment 2(1): 90-92.

4. Riley P, Glenny AM, Worthington HV, Littlewood A, Fernandez Mauleffinch LM, et al. (2017) Interventions for preventing oral mucositis in patients with cancer receiving treatment: cytokines and growth factors. Cochrane Database Syst Rev 11: CD011990.

5. Zamaro A, Zhukava T, Kulchitsky V (2018) Antitumor effects of allogenic mesenchymal stem cells. Arch Cancer Res 6: 34.
6. Shapira A, Livney YD, Broxterman HJ, Assaraf YG (2011) Nanomedicine for targeted cancer therapy: towards the overcoming of drug resistance. Drug Resist Updat 14(3): 150-163.

7. Kulchitsky VA, Alexandrova R, Suziedelis K, Paschkevich SG, Potkin VI, et al. (2014) Perspectives of Fullerenes, Dendrimers, and Heterocyclic Compounds application in Tumor Treatment. Recent Patents on Nanomedicine 4: 82-89.

8. Kirtane AR, Kalscheuer SM, Panyam J (2013) Exploiting nanotechnology to overcome tumor drug resistance: Challenges and opportunities. Adv Drug Deliv Rev 65(13): 1731-1747.

9. Sadhukha T, O Brien TD, Prabha S (2014) Nano-engineered mesenchymal stem cells as targeted therapeutic carriers. J Control Release 196: $243-$ 251 .

10. Roigas J, Massenkeil G (2005) Nonmyeloablative allogeneic stem cell transplantation in metastatic renal cell carcinoma: a new therapeutic option or just a clinical experiment? World J Urol 23(3): 213-220.

11. Yan K, Zhang R, Chen L, Chen F, Liu Y, et al. (2014) Nitric oxide-mediated immunosuppressive effect of human amniotic membrane-derived mesenchymal stem cells on the viability and migration of microglia. Brain Res 24 (1590): 1-9.

12. Guerrouahen BS, Sidahmed H, Al Sulaiti A, Al Khulaifi M, Cugno C, et al. (2019) Enhancing Mesenchymal Stromal Cell Immunomodulation for Treating Conditions Influenced by the Immune System. Stem Cells Int 2019: 7219297

13. Kulchitsky V, Zamaro A, Shanko Y, Koulchitsky S (2018) Prospects of Perineural Implantation of Stem Cells in Recovery of Neural Networks' Functions in Brain Diseases. Biomed J Sci Tech Res 10(3): 1-4.

14. Kulchitsky V, Zamaro A, Krivenchuk D Koulchitsky S. (2019) Can Nerve Trunks Serve as Railroads for Stem Cells? Biomed J Sci Tech Res 15(1): $1-3$.

15. Shanko Y, Navitskaya V, Zamaro A, Krivenko S, Koulchitsky S, et al. (2019) Application of stem cells perineural migration in patients with stroke. J Neurol Stroke 9(2): 111-112.

16. Koulchitsky S, Zamaro A, Navitskaya V, Shanko Y, Kulchitsky V, et al. (2019) Does Technique of Mesenchymal Stem Cells Perineural Migration Seem Promising in Technologies of Combined Therapy with Stem Cells? Biomed J Sci \& Tech Res 16(2): 1-3.

17. Capittini C, Bergamaschi P, De Silvestri A, Marchesi A, Genovese V, et al. (2011) Birthweight as a risk factor for cancer in adulthood: the stem cell perspective. Maturitas 69(1): 91-93.

18. Han SW, Kim YY, Kang WJ, Kim HC, Ku SY, et al. (2018) The Use of Normal Stem Cells and Cancer Stem Cells for Potential Anti-Cancer Therapeutic Strategy. Tissue Eng Regen Med 15(4): 365-380.

19. Chou YP, Lin YK, Chen CH, Fang JY (2017) Recent Advances in Polymeric Nanosystems for Treating Cutaneous Melanoma and Its Metastasis. Curr Pharm Des 23(35): 5301-5314.
ISSN: 2574-1241

DOI: 10.26717/BJSTR.2020.24.004107

Kulchitsky Vladimir. Biomed J Sci \& Tech Res

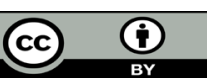

This work is licensed under Creative Commons Attribution 4.0 License

Submission Link: https://biomedres.us/submit-manuscript.php

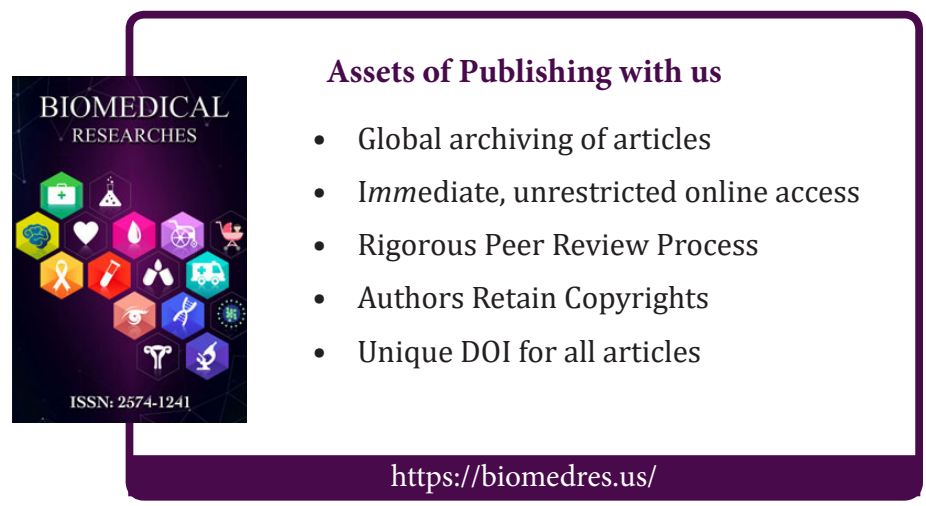

